\title{
Optimization of Environmental Parameters on Decolorization of Remazol Black B Using Mixed Culture
}

\author{
Maulin P Shah ${ }^{1, *}$, Patel KA ${ }^{1}$, Nair SS ${ }^{1}$, Darji AM ${ }^{1}$, Shaktisinh J Maharaul ${ }^{2}$ \\ ${ }^{1}$ Industrial Waste Water Research Laboratory, Division of Applied \& Environmental Microbiology Lab, Enviro Technology Limited, \\ Gujarat, India \\ ${ }^{2}$ Laboratory of Environmental Bioremediation, Narmada Clean Tech Limited (FETP), Guajrat, India \\ *Corresponding author: shahmp@uniphos.com
}

Received July 29, 2013; Revised August 19, 2013; Accepted August 20, 2013

\begin{abstract}
In the present study, an attempt was made to examine the potential of mixed culture (contains Pseudomonas putida, Psueomonas stutzeri, Pseudomonas aeruginosa, Pseudomonas mendocina) for decolorization of Remazol Black B dye in batch reactors. The effect of $\mathrm{pH}$, temperature, inoculum, initial concentration of dye and initial concentration of glucose was studied with an aim to determine the optimal conditions required for maximum decolorization and degradation. The culture exhibited maximum decolorization ability at $\mathrm{pH}$ between 7-8 and at $30^{\circ} \mathrm{C}$. A $10 \%(\mathrm{v} / \mathrm{v})$ inoculum and $1 \%(\mathrm{w} / \mathrm{v})$ glucose concentration were found to be the optimum for decolorization. A maximum of $98 \%$ decolorization was observed at $25 \mathrm{ppm}$ initial concentration of dye after 18 hours of incubation period. At higher dye concentration of $300 \mathrm{ppm}$, the removal in colour was found to be $75 \%$ in 48 hours of incubation period. The results show that the enriched mixed culture from activated sludge has an excellent potential in removal of Remazol Black B dye from wastewater under aerobic conditions.
\end{abstract}

Keywords: Remazol Black B, pH, temperature, decolorization

Cite This Article: Maulin P Shah, Patel KA, Nair SS, Darji AM, and Shaktisinh J Maharaul, "Optimization of Environmental Parameters on Decolorization of Remazol Black B Using Mixed Culture.” American Journal of Microbiological Research 1, no. 3 (2013): 53-56. doi: 10.12691/ajmr-1-3-4.

\section{Introduction}

Rapid industrialization has necessitated the manufacture and use of different chemicals in day to day life (Shah et al., 2013). The textile industry is one of them, which extensively use synthetic chemicals as dyes. Waste waters from textile industries pose a threat to the environment, as large amount of chemically different dyes are used (Shah et al., 2013). Reactive dyes, including many structurally different dyes, are extensively used in the textile industry because of their wide variety of color shades, high wet fastness profiles, ease of application, brilliant colors, and minimal energy consumption. The three most common groups are azo, anthraquinone and phthalocyanine (Shah et al., 2013). Various kinds of physico-chemical methods are in use for the treatment of wastewater contaminated with dye. These methods are not environment friendly and cost-effective and hence become commercially unattractive (Kariminiaee et al., 2007). Many microorganisms belonging to the different taxonomic groups of bacteria, fungi, actinomycetes and algae have been reported for their ability to decolourize azo dyes (Asad et al., 2007). A lot of information is available on removal and degradation of Remazol Black B using pure strains of bacteria, fungi, algae and yeast such as Shewanella strain J18 143 , Rhizopus arrhizus ,Phlebia tremellosa , Trametes versicolor, Bjerkandera sp. BOS55, P. chrysosporium, Chlorella vulgaris ,Candida tropicalis,
Saccharomyces cerevisiae, Kluyveromyces marxianus IMB3 , P. mirabilis, P. luteola, Pseudomonas sp. and $K$. rosea (Aksu et al., 2000., Kirby et al., 2000., Swamy et al., 1999., Meehan et al., 2000 ). The removal and degradation of Remazol Black B dye by various physicochemical methods have also been studied (Robinson et al., 2002., Hepel \& Hazelton., 2005., Vinodgopal et al., 1998). However, maintaining the purity of single cultures in the large scale application and their inability to degrade all different dyes present in the actual effluent are the drawbacks for their commercial application (Pearce et al., 2006, Andre et al., 2007). Therefore, the use of mixed culture seems to have more potential for large scale application at field level. The syntrophic interactions present in the mixed communities lead to complete mineralization of azo dyes (Chang et al., 2004). In the present study, an attempt has been made for the degradation and decolorization of an azo dye (Remazol Black B) using aerobic mixed culture in batch reactors. Effect of various process parameters like $\mathrm{pH}$, temperature, inoculum concentration, glucose concentration and initial concentration of dye was studied.

\section{Materials \& Methods}

\subsection{Dye Solution}

Remazol black B (RBB) used in the present study is acidic and soluble in water. A stock solution of 1000 ppm 
was initially prepared and the solutions of the desired concentrations for various experiments were obtained by successive dilution.

\subsection{Inoculum Source and Acclimatization}

Activated sludge collected from common effluent treatment plant of Ankleshwar, Gujarat, India was used as the parent source of inoculum in the present study. For enrichment of the culture, the heterogenous population was first grown aerobically in a medium containing $1 \%$ $(\mathrm{w} / \mathrm{v})$ glucose $(\mathrm{COD}=1200-1400 \mathrm{mg} / \mathrm{L})$ as the carbon and energy source and Remazol black $B$ dye. During acclimatization period, the amount of glucose was regularly checked and maintained at $1 \%$. The composition of the synthetic medium used in the present study was as follows: glucose, $10.000 \mathrm{~g} / \mathrm{L}$; Yeast extract, $0.34 \mathrm{gL}-1$; $\mathrm{NH}_{4} \mathrm{Cl}, 0.84$ gL-1 ; $\mathrm{KH}_{2} \mathrm{PO}_{4}, 0.134$ gL-1; $\mathrm{K}_{2} \mathrm{HPO}_{4}, 0.234$ gL-1; $\mathrm{MgCl}_{2} \cdot 6 \mathrm{H}_{2} \mathrm{O}, 0.084$ gL-1. The culture was gradually exposed to increasing concentrations of RBB dye in order to acclimatize the microbial culture. Successive transfers of culture $\left(180 \times 10^{5}\right)$ into fresh glucose medium containing higher concentrations of RBB upto $300 \mathrm{ppm}$ was done at $37^{\circ} \mathrm{C}$ in rotary condition. This acclimatized microbial culture was used for all experiments.

\subsection{Batch Experiments}

The experiments were performed in batch mode in 500 ml Elynmers flasks. A working volume of $200 \mathrm{ml}$ was employed throughout the study. The glucose media and dye (concentration according to the requirement i.e. 10 ppm, 20 ppm and 50 ppm) were added to the flasks. The flasks were incubated with $10 \%(\mathrm{v} / \mathrm{v})$ acclimatized inoculum. After adding glucose media, inoculum and required concentration of dye, the flasks were kept in an orbital shaker at $160 \mathrm{rpm}$ and $30^{\circ} \mathrm{C}$. The $\mathrm{pH}$ of the solution was adjusted to 5, 6, 7, 8 and 9 with $1 \mathrm{~N}$ hydrochloric acid or sodium hydroxide. In addition, control flasks containing only dye and media and without inoculum were also kept to see the abiotic decolorization, if any. All the experiments were performed in duplicate.

\subsection{Analytical Methods}

At different time intervals, the samples were withdrawn from the flasks and centrifuged at $6000 \mathrm{rpm}$ for $10 \mathrm{~min}$. to precipitate suspended biomass. The concentration of dye in the supernatant was determined by reading absorbance at 595nm. This absorbance was compared with standard curve plotted using different concentrations of the dye. The measurement of absorbance and centrifugation were done by using Shimadzu UV- 1800 spectrophotometer and Remi model centrifuge, respectively.

\section{Results and Discussion}

\section{1. pH Effect}

Effect of $\mathrm{pH}$ (5-9) on decolorization with time of Remazol Black B at 100 ppm initial concentration of dye with $10 \%$ inoculum is shown in Figure 1. The figure clearly shows that the percentage removal of dye increased with increase in time irrespective of $\mathrm{pH}$. The maximum removal (96\%) of dye was found at $\mathrm{pH} 7$ and 8 after 30 hours of incubation period. Further increase in $\mathrm{pH}$ beyond 8 and decrease in $\mathrm{pH}$ below 7 resulted in decreased percentage removal of dye. The optimum $\mathrm{pH}$ was found to be between 7 and 8 for maximum removal of dye. The $\mathrm{pH}$ has a major effect on the efficiency of dye decolorization, and the optimal $\mathrm{pH}$ for color removal is often between 6.0 and 10.0 for most of the dyes (Chen et al., 1999). The $\mathrm{pH}$ tolerance of decolorizing bacteria is quite important because reactive azo dyes bind to cotton fibers by addition or substitution mechanisms under alkaline conditions and at high temperatures (Aksu Z., 2003).

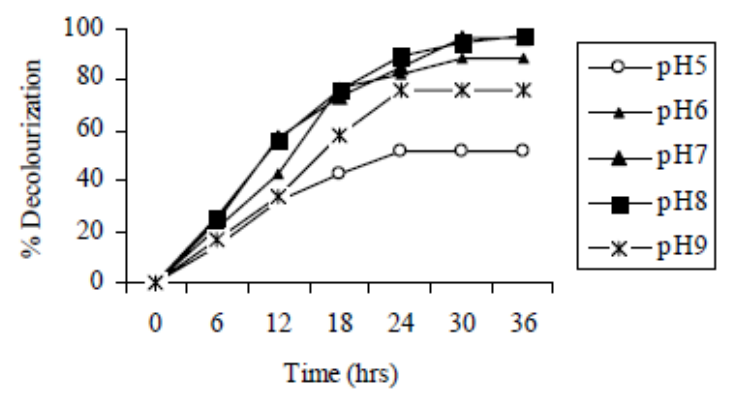

Figure 1. Effect of $\mathrm{pH}$ on decolorization with time

\subsection{Inoculum Concentration Effect}

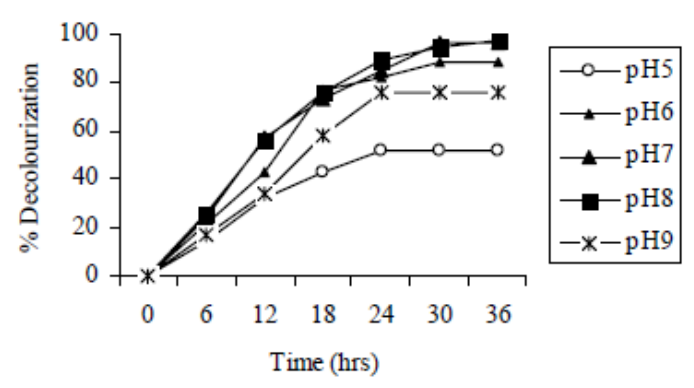

Figure 2. Effect of inoculum concentration on decolorization with time

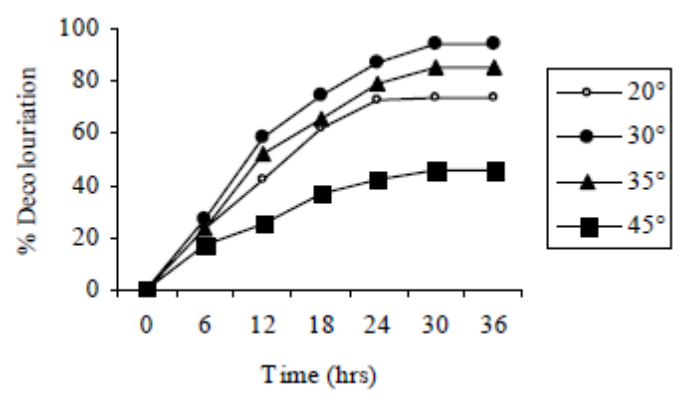

Figure 3. Effect of temperature on decolorization with time

Figure 2 shows the effect of inoculum concentration (5$20 \%$ ) with time on decolorization of dye at 100 ppm initial concentration. It is clear from the figure that percentage removal of dye increased with an increase in time for all concentrations of inoculum. The percentage removal of dye rapidly increased till 30 hrs then became constant at all concentrations of inoculum. After 36 hours the percentage removal of dye was found to be 71, 90, 94 and $96 \%$ at inoculum concentrations 5, 10, 15 and 20\% respectively. There was no significant difference in percentage removal at 10,15 and $20 \%$ inoculum concentrations and hence $10 \%$ Effect of Temperature Figure 3 shows decolorization of dye with time at different temperatures $\left(20,30,35\right.$ and $\left.45^{\circ} \mathrm{C}\right)$ at $100 \mathrm{ppm}$ 
initial dye concentration and $10 \%$ inoculum. It is clear from the figure that percentage removal of dye increased with an increase in temperature from 20 to $300 \mathrm{C}$. The percentage removal of dye decreased with further increase in temperature up to 450C. Decolorizing activity was significantly suppressed at $45^{\circ} \mathrm{C}$, this might be due to the loss of cell viability or deactivation of the enzymes responsible for decolorization at $45^{\circ} \mathrm{C}$ (Cetin et al., 2006). Effect of glucose concentration Figure 4 shows the effect of glucose concentration $(0.10-2 \%)$ on decolorization with time performed at $100 \mathrm{ppm}$ initial concentration of dye, $10 \%$ inoculum concentration and at $300 \mathrm{C}$ in an orbital shaker at $180 \mathrm{rpm}$. The figure clearly shows that maximum removal of dye (96\%) was achieved after 30 hours of incubation period using $1 \%$ glucose media. Further increase in glucose concentration up to $2 \%$ resulted in decreased removal up to $57 \%$. However, the lower concentration of glucose also inhibited the decolorizing activity of mixed culture. The reason for low decolorization at $0.10 \%$ and $0.25 \%$ might be that low glucose concentrations could not meet the growth requirements of the microbes. When the glucose concentration was $2 \%$, the bacteria could utilize glucose preferentially, thus resulting in lower decolorization extent. In the present study it was found that $1 \%$ glucose concentration is optimum for decolorization of Reamzol Black B dye. Effect of initial concentration of dye Figure 5 shows the effect of initial concentration of dye ranging

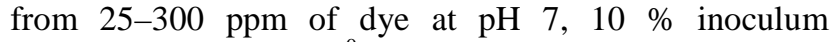
concentration and at $30^{\circ} \mathrm{C}$. It is clear from the figure that percentage removal of dye increased with an increase in time irrespective of initial dye concentration. Further, percentage removal of dye decreased with an increase in dye concentration. Percentage removal of dye was found to be $98,94,90,88,85,81$ and 75 at 25, 50, 100, 150, 200, 250 and $300 \mathrm{ppm}$ initial concentrations of dye, respectively.

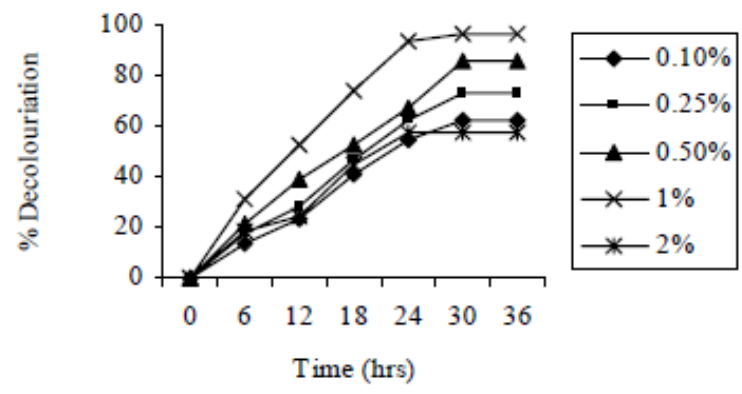

Figure 4. Effect of glucose concentration on decolorization with time

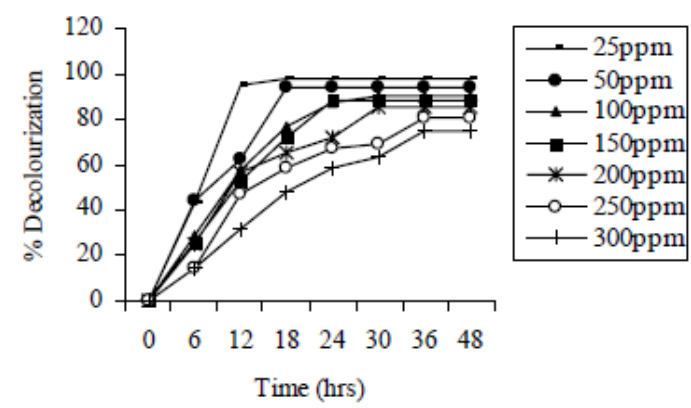

Figure 5. Effect of initial concentration of dye on decolorization with time

\section{Conclusion}

The present study reveals that enriched aerobic mixed culture can be used successfully for decolorizing Remazol Black B dye. The culture exhibited maximum decolorization ability at $\mathrm{pH}$ between 7-8 and $30^{\circ}$ C .Moreover, $10 \%(\mathrm{v} / \mathrm{v})$ inoculum and $1 \%$ glucose concentrations were found to be optimum for decolorization. At 25 ppm initial dye concentration a maximum of $98 \%$ removal of color was observed after 18 hours. At higher dye concentration of $300 \mathrm{ppm}$, the removal in color was found to be 75 after 48 hours of incubation period. On the basis of the results of the present study suitable strategy can be developed for the treatment of waste water contaminated with dye.

\section{References}

[1] Maulin P Shah, Kavita A Patel, Sunu S Nair, Darji AM (2013) Optimization of Environmental Parameters on Microbial Degradation of Reactive Black Dye. Journal of Bioremediation \& Biodegradation (USA) 4:3.

[2] Maulin P Shah, Kavita A Patel, Sunu S Nair, Darji AM (2013) Bioremoval of Azo dye Reactive Red by Bacillus spp. ETL-1982. Journal of Bioremediation \& Biodegradation (USA) 4:3.

[3] Maulin P Shah, Kavita A Patel, Sunu S Nair, Darji AM (2013) Microbial degradation of textile dye (Remazol Black B) by Bacillus spp. ETL-2012. Journal of Bioremediation \& Biodegradation (USA) 4:2.

[4] Maulin P Shah, Kavita A Patel, Sunu S Nair, Darji AM (2013) Microbiolgical removal of crystal violet dye by Bacillus subtilis ETL-2211. OA journal of Biotechnology (UK), Feb 01;2(1):9.

[5] Kariminiaae, Hamedaani.; Sakurai, A.; Sakakibara, M.; Decolorization of synthetic dyes by a new manganese peroxidaseproducing white rot fungus. Dyes Pigments. 2007 (72) 157-162.

[6] Asad, S.; Amoozegar,M.A,; Pourbabaee, A.A.; Sarbolouki, M.N.;Dastgheib, S.M.M. Decolorization of textile azo dyes by newly isolated halophilic and halotolerant bacteria. Bioresource Technology. 2007, 2082-2088.

[7] Aksu, Z.; Tezer, S. Equilibrium and kinetic modelling of biosorption of Remazol Black B by Rhizopus arrhizus in a batch system: effect of Temperature. Process Biochemistry.2000 (36) 431-439.

[8] Kirby, N.; Marchant, R.; McMullan, G. Decolourisation of synthetic textile dyes by Phlebia tremellosa. FEMS Microbiology Letters. 2000 (188) 93-96.

[9] Swamy, J.; Ramsay, J.A.The evaluation of white rot fungi in the decolouration of textile dyes. Enz Microbial Technology.1999 (24) 130-137.

[10] Aksu, Z.; Donmez, G. Combined effects of molasses sucrose and reactive dye on the growth and dye bioaccumulation properties of Candida tropicalis. Process Biochemistry. 2005 (40) 2443-2454.

[11] Meehan, C.; Banat, IM.; McMullan, G.; Nigam, P.; Smyth, F.; Marchant, R. Decolorization of Remazol Black-B using a thermotolerant yeast, Kluyveromyces marxianus IMB3. Environment Internatioanl. 2000. (1-2) 75-79.

[12] Robinson, T.; Chandran, B.; Nigam, P. Effect of pretreatments of three waste resiudes, wheat straw, corncobs and barley husks on dye adsorption. Bioresour Technol. 2002 (85) 119-124.

[13] Hepel,M.; Hazelton,S. Photoelectrochemical Degradation of Diazo Dyes on Nanostructured Electrodes Electrochim Acta. 2005 (50) 5278-5291.

[14] Vinodgopal, K.; Peller, J.; Makogon, O.; Kamat, P.V. Ultrasonic mineralization of a reactive textile azo dye, Remazol Black B. Water Research. 1998(32) 3646.

[15] Pearce, CI.; Lloyd, JR.; Guthrie, JT. The removal of colour from textile wastewater using whole bacterial cells: a review. Dyes and Pigment. 2003 (58),179-196.

[16] Andre, BDS.; Francisco, JC.; Jules, BVL. Review paper on current technologies for decolourisation of textile wastewaters: perspectives for anaerobic biotechnology. Bioresource Technology. 2007 (98) 2369-2385. 
[17] Chang, Jo-Shu.; Chen, Bor-Yann.; Lin, YS. Stimulation of bacterial decolorization of an azo dye by extracellular metabolites from Escherichia coli strain NO3. Bioresource Technology. 2004 (91) 243-48.

[18] Chen, K.C.; Huang, W.T.; Wu, J.Y.; Houng, J.Y. Microbial decolorization of azo dyes by Proteus mirabilis, Journal of Industrial Microbiology and Biotechnology. 1999 (23) 686-690.
[19] Aksu, Z. Reactive dye bioaccumulation by Saccharomyces cerevisiae.Process Biochem. 2003(10) 1437-1444.

[20] Cetin, D.; Donmez,G. Decolorization of reactive dyes by mixed cultures isolated from textile effluent under anaerobic conditions. Enzyme and Microbial Technology. 2006 (38) 926-930. 